This item was submitted to Loughborough's Research Repository by the author.

Items in Figshare are protected by copyright, with all rights reserved, unless otherwise indicated.

\title{
Understanding the experiences of asylum seekers
}

PLEASE CITE THE PUBLISHED VERSION

http://dx.doi.org/10.1108/IJMHSC-06-2013-0016

PUBLISHER

(C) Emerald

VERSION

AM (Accepted Manuscript)

LICENCE

CC BY-NC-ND 4.0

REPOSITORY RECORD

Liebling, Helen, Shani Burke, Simon Goodman, and Daniel Zadasa. 2019. "Understanding the Experiences of Asylum Seekers". figshare. https://hdl.handle.net/2134/16523. 


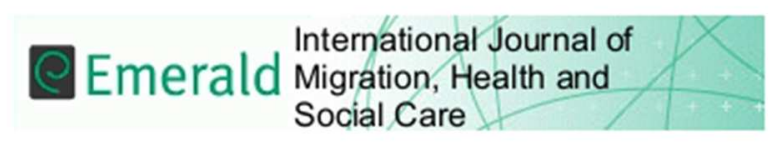

\section{Understanding the Experiences of Asylum Seekers}

\begin{tabular}{|r|l|}
\hline Journal: & International Journal of Migration, Health and Social Care \\
\hline Manuscript ID: & IJMHSC-06-2013-0016.R1 \\
\hline Manuscript Type: & Academic Paper \\
\hline Keywords: & $\begin{array}{l}\text { Asylum seekers, Experiences, Understanding, United Kingdom, Thematic } \\
\text { analysis }\end{array}$ \\
\hline \multicolumn{2}{|l}{} \\
\hline
\end{tabular}




\title{
Understanding the Experiences of Asylum Seekers
}

\begin{abstract}
Purpose

The purpose of this research is to highlight the key issues of concern for asylum seekers in the UK by focussing on their in depth talk about their experiences, a so far neglected element in the current debate about asylum seeking.
\end{abstract}

\section{Methodology}

The study involved thematic analysis of asylum seekers' accounts of their lives in their country of origin, their journeys to the UK and experiences following arrival. Nine participants took part in semi-structured interviews.

\section{Findings}

Analysis resulted in seven themes; the importance of safety, negative experiences of the Home Office, support, emotional effects, significance of family, hopes for the future and the positive experiences of living in the United Kingdom.

\section{Research Implications}

Asylum seekers largely left their countries of origin to escape conflict, persecution, violence, arranged marriages and rape. They reported safety as a key concern and for this reason they were scared to return home.

\section{Practical implications}

The research found Asylum seekers have fled traumatic situations and then have a difficult time in the UK. A more compassionate and supportive approach is needed. Policy recommendations are made with the aim of improving service responses.

\section{Social implications}

The research demonstrates that the public understanding of asylum seeking does not match asylum seekers' experiences and increased knowledge may help to improve this (mis) understanding. 


\section{Originality}

There is currently a lack of literature and empirical investigation of this subject area, so this research makes a contribution to the field of understanding asylum seekers' experiences. The paper's focus is original and important combining asylum seekers' accounts of their experiences following arrival in the UK. This subject is strategically important due to the pressing need to develop holistic and culturally sensitive research, which bridges and informs academia, more sensitive service responses and civil society.

Key words: Asylum seekers; experiences; understanding; United Kingdom; thematic analysis

\section{Introduction}

Reasons for claiming asylum in the UK

The countries from which the most asylum applications in the UK were recently made are Pakistan, Iran, Sri Lanka, Afghanistan and Libya (UNHCR, 2011). Research shows that asylum seekers have fled from dangerous conditions in their country of origin including oppression and violence (Neumayer, 2005), and have often survived traumatic experiences including the murder of family members, sexual violence and rape (Anonymous authors, 2012) and torture (Benham, 2004). Far from being people who are always set on reaching the UK, the evidence suggests that asylum seekers often know very little about the UK or its immigration system when they arrive. Gilbert and Koser (2004) found that many did not choose their own destination, and their arrival in the UK was linked to either having to flee their country of origin in a hurry, or through the use of agents.

\section{Treatment of Asylum Seekers in the UK}

Once in the UK, there are a range of measures in place to deal with asylum seekers, many of which can be considered to be harsh (e.g. anonymous author(s), 2007). Asylum seekers have a lack of rights, and measures have been made to decrease the number of asylum applications in the UK (Bloch, 2013; Hynes and Sales 2009). 
Asylum seekers tend to be housed in deprived areas (Darling, 2011; Deuchar, 2011) which can exacerbate problems with community cohesion. Asylum seekers are not allowed to work (Smyth and Kum, 2010) and have to rely on income support, which is 30 percent lower than the usual rate of financial support that a British person receives (Refugee Council, 2012). Together, these factors can lead to asylum seekers living in the UK experiencing exclusion, inequalities of access to services and marginalization (Hynes and Sales, 2009).

There is evidence to suggest that decisions about asylum cases are made with the aim of reducing asylum into the UK. Souter (2011) has shown how there is a presumption that an applications will be refused, what he terms a 'culture or disbelief' (2011: 48). Further, Hardy (2003) demonstrated how workers in the Home Office lack the appropriate knowledge about asylum seekers' countries of origin required in order make accurate decision and service providers are also constrained by funding cuts (Dorling and Hurrell, 2012). The result of this is that many asylum seekers, who arguably have valid cases to seek refuge, have their claims refused. Once in this situation, failed asylum seekers receive no kind of financial support or housing (Bloch, 2013) which leads to further social exclusion.

The harsh asylum policies in the UK results in constructions of asylum seekers as a 'threat', which further leads to a sense of crisis and encourages hostility towards them (Mulvey, 2010; anonymous author(s), 2012). Asylum seekers are presented as being an economic burden to British taxpayers (e.g. Capdevila and Callaghan, 2008), which exacerbates the prevailing view that they are a burden and a drain to resources (anonymous author(s), 2011). While they are technically allowed to work under very specific conditions, in reality this amounts to a ban on working (Gower, 2011). In addition to harsh policies, in the UK asylum seekers receive day-to-day prejudice and physical violence (Kirkwood, 2012).

\section{The effects of harsh treatment on asylum seekers}

The hostility that asylum seekers receive has negative implications for their psychological well-being (Leudar et al., 2008). The uncertainly that the asylum 
process creates and the potential for deportation to the country of origin creates anxiety, (Anonymous author(s), 2012) which results in and further exacerbates mental health difficulties including post-traumatic stress disorder (Lawrence, 2004), depression, and suicidal feelings and behaviours (Bernardes et al., 2010). Mental health problems in asylum seekers have also been found to be linked to being unable to work as this increases feelings of isolation and makes integration difficult (e.g. Strijk, et al., 2011). Research has found that asylum seekers want to work as soon as possible, as living off benefits further contributes to their mental health problems (Fozdar, 2009). Despite having complex healthcare needs, previous research has shown that there is inadequate support available for asylum seekers and language barriers, poverty, and difficulty in accessing transport also prevent asylum seekers from accessing healthcare support (McKeary and Newbold, 2010). In addition to this, stigma regarding sexual abuse makes it difficult for survivors of this to seek appropriate help (Anonymous author(s) 2012). The particular needs of women asylum seekers, has also been raised as an urgent concern with many having experienced gender-based persecution and their failed asylum leading to exacerbation of traumatic effects, including suicidal thoughts (Dorling et al. 2012).

\section{Rationale for the current study}

Asylum seekers are often fleeing distressing and traumatic situations (e.g. Neumayer, 2005), have a difficult journey to safety and are subject to further difficulties and barriers once they reach the UK (e.g. Bloch, 2013), all of which can have serious and negative effects on their health and well-being. While extant literate highlights some difficulties asylum seekers face in their counties of origin and once they reach the UK, there is a lack of thematic research that investigates asylum seekers' experiences in their host country, and specifically in the UK. Therefore the aim of the current study is to investigate: asylum seekers' experiences in the UK.

\section{Methodology}

Nine asylum seekers were recruited and volunteered to be interviewed for the purpose of the research (see Table 1). They were recruited through a refugee centre in 
Coventry and interviewed using a semi-structured interview schedule. Coventry Refugee and Migrant Centre, CRMC, state:

"We are a local Charity with a mission to identify and meet the needs of refugees and migrants in Coventry through the provision of projects and services which helps them to settle into local communities, supporting effective integration and encouraging them to make a full contribution to the life of the City. In addition to this we help the destitute through our work with the Coventry Destitution Partnership, which we are proud to chair. Clients of CRMC are assisted with all aspects of beginning a new life here, from being helped with nationality and immigration issues through to housing, employment and learning about life in Coventry. We have a dedicated team of approximately 30 paid staff and nearly 100 volunteers providing our services to clients who arrive here from all four corners of the globe."

(http://www.covrefugee.org)

Interviews were conducted at the refugee centre between May and July 2012. Interviews lasted between 20-50 minutes. One interview (Participant six) was carried out with the assistance of an interpreter; the remaining eight were carried out in English. Interviews were tape recorded and transcribed verbatim by the second author. The interview questions focused on participant's experiences in their home country, their reason for choosing the UK as their destination, their experiences with the Home Office, sources of support and experiences of living in the UK, the effects of their experiences and their hopes for the future.

Although a small sample size was utilised, the themes arising from the data were highly salient to those interviewed and provide further information regarding issues facing asylum seekers in the UK today. The limitations of using a small sample are addressed below. Thematic analysis provides an account of the key themes to arise out of the interviews with all of the participants. It is a method for identifying, analysing, and reporting patterns within the data (Boyatzis, 1998). The approach and procedures for thematic analysis illustrated by Braun \& Clarke (2006) were utilised. 
[Table One about here]

\section{Results}

Thematic analysis of the interviews identified seven themes that related to important aspects of the participants' experiences. These are outlined in table two and are addressed in turn below.

[Table Two about here]

\section{The importance of Safety}

All participants had fled from their home country due to fears regarding their safety. There were a wide range of reasons for this, including war and political conflict (P1, P3, P8) an unwanted arranged marriage (P7), and experiences of gang violence and rape (P9). For some participants, as with participant one's account below, their experiences had been ongoing from an early age and affected their whole community. Participant one describes his account of his home country: "I don't remember any good days... [there] always was fighting...I never remember any days that were you know good [laughs]' (P1, 54-59).

All of the participants interviewed chose to come from their home country to the UK because they perceived it to be a safe country, as shown by Participant eight's account, where she highlights that even though she was 'sleeping on the streets', she felt safer compared to in her home country:

I like [a] safe country you know I don't see any problem like this it's better for me even I sleep outside no [one will] kill me no [one] makes problems ( $\mathrm{P} 8$, 132-136).

The participants we spoke to perceived they were safe in the UK because they were as far away as possible from danger, or could not be found by people deemed to pose a threat to their life from their country of origin. Other reasons mentioned by participants included UK having 'fair laws' (P5) or being viewed as democratic (P7). 
For some participants (P1, P2, P7, and P8) they were told by a trusted friend or colleague that they would be safe in the UK.

Some of the participants interviewed were unable to return to their home country due to fear and danger. When participants were asked if they would ever like to return to their home country, the response "'never"' was used. For some participants, such as participant five, they related that they would rather die in the UK than return to their home country:

I don't want to return back to my country because they will kill me. Before they send me to my country better I kill myself here I don't want to be returned back to my country (P5, 74-77).

However, some participants expressed a wish to return as they liked their home country, but had little hope that the circumstances that caused them to flee in the first place would have changed. Here participant 7, who fled from an unwanted arranged marriage, describes how she likes her home country, but her situation prevents her from returning:

I like my home country...my country is okay...but the problem is security of my life. That's my problem (P7, 598-602).

\section{Negative experiences of the Home Office}

The Home Office were described by participants as treating asylum seekers inhumanly, and were experienced as an 'uncaring system' that make participant's feel they weren't believed. Some participants complained that the Home Office was very slow, and that they had been waiting several years for an answer regarding their asylum application. This meant that participants found it difficult to make any plans for the future. The uncertainty of their circumstances caused them further distress. Here participant one demonstrates how the slow pace of the Home Office procedures affected him: "It's hard when you don't know what's going to happen to you know you think about it every day that you [have] been here ten years[and] why they don't want 
to let you to stay here" (P1, 468-471).

Participants we spoke to found the Home Office to be very controlling; for example having to report every week to the police, which was often a long distance for participants to travel to resulting in additional expenditure which they could not afford. For one participant (Participant 7), this was not practical, as she had recently had given birth to a premature baby. Reporting not only disrupted her routine, but also affected being able to look after her newborn child as she explains:

They've got a specific time you have to come if they saying you have to come at $11 o^{\prime}$ clock you have to be there at 11 o'clock. If you try to make the excuse they won't bother to take your excuses, you see and they forget that having this little one and going there to report is not easy (P7, 456-461).

The participants interviewed had a lack of understanding about the way the Home Office worked and were unsure about the current status of their application, for example participant 1 said "our case is God knows where" (Participant 1, lines 573574), and another participant said: “when you going asylum you don't know anything...you don't know what's going on in the Home Office you don't know the way the Home Office they react" (Participant 7, 419-420). Participants often did not know what stage the application was at, or how long they would expect to have to wait before receiving an answer. For participant seven, she felt that it was unfair that she had to report every week to the police station, when she had never even been informed about why she has to do this. Many participants thought about their applications constantly, and the continuous uncertainty created a lack of hope that their applications would be accepted.

For participants who had their application for asylum rejected, there was criticism of the Home Office, which was viewed as lacking knowledge about participants' home countries and incorrectly deeming their countries of origin to be safe, suggesting that returning would be impossible. Participant three demonstrated his disappointment with the Home Office for claiming that his home country was safe, something that made him change his mind about viewing the UK as a safe country. Participant seven argued that the Home Office did not have the first-hand experience or knowledge re- 
quired of what it is like to live in her Home Country.

Other negative experiences that were described by participants were regarding the treatment they received, in particular by staff at the Home Office. Some of the participants stated that staff they dealt with appeared to be more concerned with sending them back to their country of origin, than offering them safety in the UK, for example "because this Home Office they do anything to kick you out of the country" (Participant 3, 233-234). Participant three reported that the Home Office did not respect applicants who were not white, whilst participant four who had previously been sent back to her country by force, said that the Home Office treated her "like an animal" "(P4, 103).

\section{Experiences of support in the UK}

Participants reported that the Coventry Migrant and Refugee Centre was good at providing them with practical support such as food, but that they didn't find the centre to be especially helpful with their applications for asylum, as they felt staff lacked the ability to do anything to influence the Home Office, for example participant one said:

You know they [are] trying these people... trying hard as well but the problem is [the] Home Office they don't care they...they send many letters... I [have] been sending many letters from here but they never respond (P1, 882-885).

All of the participants did not have any stable accommodation; reporting that they lived with friends (e.g. participants 2 and 5) and moved frequently between insecure accommodations (e.g. participant 3). There was evidence of destitution, with some participants 'living on the streets', and participant nine in particular was very distressed and crying as she talked about this; she described how she did not have anywhere relaxing to take her antidepressant medication:

I don't have somewhere to relax... I just walk and walk and I leave the place at 8 am in the morning and I cannot go back till 9pm...it is too long. During the day I don't have anything to eat (P9, 189-191). 
Two participants reported unpleasant experiences whilst living in UK, which made them, feel unsafe. Participant four experienced racist attacks when people threw eggs at her house and punched her door and participant six said that people laughed at him because he doesn't speak English.

Although participants voiced that there was limited support in the UK, there were some sources reported to be helpful. Some of the participants interviewed gave positive reports about the health services they had experienced since arriving in the UK, particularly Participant seven who displayed empathy and appreciation for the hospital staff who helped her when her baby was born premature, saying that their work is " not easy" $(\mathrm{P} 7,680)$. Her experiences had been so positive that in the future she wanted to work as a nurse.

Friends were also identified as a significant source of support for asylum seekers. As well as emotional support; they provided practical support such as food and drinks, and somewhere to stay. As described above, for some participants living with friends prevented them from living on the streets and becoming destitute. Having friends who were also asylum seekers meant that participants could talk about their situation and share their experiences of the asylum processes and systems. Participant four described her distress when her friend who was also an asylum seeker was deported back to her home country, which in addition to upsetting her, increased her anxiety about her own situation.

Two of our participants found sharing with others of the same gender or with others from similar cultures helpful. Participant eight found gender specific support through a women's group they attended was significant in assisting her, providing a forum for sharing difficult experiences, increasing solidarity and resilience. Participant three described how he felt a sense of community with his friends in the UK who were from similar cultures to him, and compared it to the sense of community that he had back in his home country:

Yeah they help because normally we we black people we stick together you know we help each together ... we help yeah we have that sense in Africa (P 3, 273-277). 
To summarise, this theme highlights the lack of support available to the group of asylum seekers interviewed and constraints to the refugee centres' effectiveness with the Home Office. Some of the asylum seekers interviewed experienced racist attacks and had a lack of secure accommodation. However, some sources of support for asylum seekers are identified, particularly with regards to the refugee centre providing support groups, healthcare, and friendships. Participants displayed empathy and appreciation for their friends who had prevented them from being destitute.

\section{Emotional effects of being an asylum seeker}

Three participants referred to having mental health problems (Participants 4, 8 and 9). Two of the participants interviewed were receiving medical treatment for depression and anxiety, and reported being suicidal. Words such as "depressed" and "stressed" were regularly used during these interviews. Whilst participant eight and participant nine were talking about their suicidal feelings, their talk was erratic, and they were both very tearful. For instance, participant nine said:

I am so stressed and have so many headaches. I would really prefer to kill myself because my life is bad and I cannot go back there (P 9, 67-68).

Participant eight frequently referred to her suicidal feelings as "scary," and expressed her fear of seeking medical help from medical professionals:

Even I want to go to see the Doctor I am scared maybe the Doctor says maybe [I am] crazy like this...I am not crazy ... I don't go... I am scared (P 8, 109$115)$.

Participants also reported feelings of loneliness and isolation, which were increased by coming to the UK on their own and not being able to speak English. The situation of being unable to work further increased their feelings of isolation. Without having a decision on their application, some of the participants felt "trapped", as they felt they did not have the freedom to make plans or go anywhere that they wanted to go. For example, participant seven highlights: 
I'm just staying indoors not going anywhere...because I'm (in) this situation with this Home Office my life is just like sticking on the same thing (P7, 646649).

Participant seven also described how she couldn't go anywhere outside of Coventry due to having to report weekly, which she described as being like a "prisoner" (P 7,796).

In summary, this theme encapsulated the extremely negative emotional effects of participants' experiences on their well-being. Some of the participants experienced depression, anxiety and suicidal tendencies, which are common effects of traumatic experiences. Participants also reported feeling isolated and trapped, which they described as making them worse due to a variety of reasons. This included having few opportunities, their extremely limited entitlement to work, as well as not having a decision on their asylum application.

\section{Significance of Family}

Some of the participants spoken to had met their partners in the UK and had children who had been born in the UK. For these participants, they described their family that made the UK feel like home for them. They described a sense of responsibility to stay in the UK and look after their children (see also anonymous author(s) 2014).

For some participants they described no longer having any connections with family back in their home country due to their families being killed, it being unsafe to contact them due to the seriousness of why they left or having to flee without them. Participant eight and Participant nine did not know the whereabouts of their family, and were clearly very upset when talking about this. Having no family in their country of origin was sometimes given as a reason why participants wished to stay in the UK, as there were no longer the supportive networks of family and friends in their home country. For one participant she had been forced to "cut off" her family as the threats that led to her leaving also placed her family members at great risk so she did not contact them in order to protect herself and her family members saying: 
I do not know about family I leave that place. I could not contact anyone once this happened to me. I can't think anything about family now as I had to give that up (P 9, 76-77).

This theme demonstrates the importance of family to participants, particularly as a reason to stay in the UK. This was either due to having a family in the UK, or losing connections with or experiencing the murder of family in their home country.

\section{Hopes for the future}

Participants' hopes for the future were ordinary desires that many would view as basic needs. For almost all of the participants interviewed, the main hope for the future was to work and be able to pay their own way and earn a living. Participant three described wanting to work "like everybody normally work" (P3, 714-715). Whilst some participants desired to take any job, including voluntary work, two participants (P5 and P7) wanted jobs related to their own personal experiences, wanting to help others who had been in a similar situation to themselves. As well as exacerbating isolation being unable to work increased participants' feelings of desperation and boredom.

Participants described wanting a secure place of their own to stay, for basic reasons including safety and stability, as well as having their own privacy to get dressed, or to have somewhere comfortable to sleep. Participant nine said:

I don't need so many things but if I had somewhere to sleep it would be better even if I take my medicine I would have somewhere to relax as when I take my medicine I feel like I need to relax (P 9, 187-189).

Another hope for the future was indefinite leave to remain, or at least a decision on their asylum application. The term "legal" was used when talking about this hope for the future, as well as wanting to become "British". Participant five described how if he received his indefinite leave to remain, his "mind will be at peace" (P5, 223). 
To summarise, this theme illustrates participants' hopes for their future are very ordinary, including having employment. Participants also reported wanting indefinite leave to remain, and somewhere secure to live.

\section{Positive experiences of living in the $U K$}

Participants five and seven both reported enjoying living in the UK, particularly with regards to there being higher security than existed in their home countries, and a sense of action being taken if crimes were committed. The police were talked about in a positive way and described as being "fair" in contrast to the police in home countries where words such as "corruption" were used. Participant seven describes the comparison between the police in the UK to her country of origin, using the scenario of a murder to demonstrate what she meant:

Because every time it's like you hear that people have been killed but they don't know who killed that person but after two days or whatever they find the person and they punish the person that's the way it is. In Malawi it's just like that if you been killed and they don't even much bother then (P 7, 402-407).

Other positive comments made were about British people being "Very friendly kind" (Participant 1, 890) As an example, participant five felt more comfortable and said he felt "free" in Britain, which related back to the theme of the importance of safety. Participants such as participant eight said that even though he was depressed and suicidal, he knew he was safe in Britain, which was more desirable than returning to his home country where he would be in danger.

This theme reveals that participants are generally happy living in the UK, particularly as they experience it as safer than their home country, with a more responsive justice system. Even those participants we spoke to who have mental health problems including anxiety, depression or suicidal tendencies preferred to live in the UK because they knew that they were safer here than if they returned to their home country. 


\section{Discussion}

The research found that the key reason that participants gave for coming to the UK was fleeing dangerous and traumatic situations to seek refuge and safety, and due to the fact that they are unable to return to their home country (see anonymous author(s). 2013). Participants reported experiencing traumatic events in their home country including rape, war and conflict, and murder and loss of family members; a trend that is consistent with previous research (see Neumayer, 2005; anonymous author(s), 2012). Participants were explicit about the danger and the likelihood of death that they would face if they returned home. Although based on a small sample size, this adds to the argument that asylum seekers are not likely to be in the UK for free benefits, a common argument used by opponents of asylum seekers (Sales, 2002; Schuster and Bloch, 2002). Contrary to this, the current study found that they are in the UK as it provides a 'safe haven', which may be preventing them from dangerous situations in their country of origin, including being killed. Whilst participants interviewed were glad to be safe in the UK, the lack of stability and the constant threat of potentially being made to return home has been shown to lead to considerable anxiety for those we spoke to who had already had to flee from extremely upsetting and dangerous situations.

A further theme that emerged from this study is the negative impact that the asylum process and the Home Office approach has on the lives of asylum seekers in the UK (see Spicer, 2008). Current policy states that asylum seekers who are destitute can apply to the UK Border Agency for accommodation (Gower, 2013). However, despite this our study found that the lack of accommodation for asylum seekers was a major problem to the extent that some of the participants interviewed were destitute, meaning that they had no fixed address, often lived in insecure situations and relied on friends for somewhere to sleep to avoid being 'out on the streets.'

There were conflicting findings related to asylum seekers' experiences of health systems in the UK; one participant had positive reports regarding the maternity care in the UK, while another participant expressed her fear of seeking medical help. However, a theme that emerged was that treatment tended to be medical in focus (usually medication only), rather than utilising a culturally sensitive, collective and 
holistic framework for mental and physical health responses that have been found to be more appropriate for those fleeing difficult experiences from non-western cultures (anonymous author(s) 2009; anonymous author(s), 2008).

The role and importance of the family was highlighted by the participants in the study. The loss (often due to murder) of family members (and parents in particular) was often given as a reason for seeking asylum in the first place. As a result, participants described feeling that they no longer had any connection with their country of origin, as without their families it was not felt to be 'home' at all. This seemed especially true of those participants that had arrived in the UK as unaccompanied minors (for example participant one) which further suggests that asylum seekers are particularly vulnerable.

Despite the often harrowing conditions that forced the participants to leave their country of origin and the difficulties that they have faced while in the UK, participants nevertheless reported some positive aspects of living in the UK. For example, participants had positive experience of the police in the UK, especially when compared to their countries of origin, and compared the UK with their home countries in terms of justice. This again highlights the importance of safety to the participants in this study. In addition to this, many participants were very happy in their lives in the UK and spoke fondly of the cities they lived in, as well as the residents of those cities. Participants generally reported enjoying a range of aspects of British culture and very much wanted to participate in and contribute to it. This certainly differs from the presentation of asylum seekers as hostile towards their host country, unwilling to integrate or participate in the host country, or wishing simply to take from it. The desire of participants interviewed in the study to work and pay taxes suggests this.

Participants' hopes for the future generally fell into two categories, gaining indefinite leave to remain and 'normal' wishes. In terms of indefinite leave to remain, it is perhaps not surprising that participants expressed a desire to be allowed to stay in the country; if this were to happen they would officially become refugees and would be guaranteed safety for life, which would remove much of the anxiety that they are currently experiencing. The other more 'normal' wishes that the participants expressed can only really come to fruition if they are granted leave to remain, and 
they hopes for the future are broadly in line with what would be expected for many British people, as they reported wanting to have a normal job so that they can support themselves and contribute to the country in which they live.

\section{Practical and social implications}

Although the themes that emerged from the current study are based on a small sample, we discuss their practical and social implications for further development by policy makers, service providers and asylum advocates. It is anticipated that if these are attended to it will mark a start in some valuable transitional steps towards better responses and treatment for asylum seekers in the United Kingdom.

The current research identified that participants have a lack of understanding about the Home Office system, and therefore we recommend that the Home Office provides clearer and more detailed information to asylum seekers about what stage their application is at, and about the asylum system in general. This would assist to reduce some of the anxiety that asylum seekers experience over their uncertain situation.

More fundamentally, a shift is needed away from the "culture of disbelief" (Souter, 2011:48). This means that asylum decisions are based on returning as many asylum seekers as possible (Hardy, 2003 and as we demonstrated above), rather than based on individual need and, importantly, the safety of the applicant. Despite recent policy initiatives (see Gower \& Hawkins, 2013), Government policy still needs to shift away from the focus on returning people; often into dangerous situations including death, and towards protecting those in need. Perhaps more importantly, politicians and the media need to shift attention onto the humanitarian benefits and needs of asylum seekers, rather than focussing on the possible (and contentious) economic burden they may bring (Rowthorne, 2008; Sales, 2002) by inaccurately presenting them as economic migrants (e.g. anonymous author(s) 2007).

Support that was found to benefit some of our asylum seekers included sharing with like-minded others in groups (see Benham, 2004; Deuchar, 2011). As a result it is recommended that further support groups are established by services. In association with this we additionally recommend that where required, (and our analysis suggests 
that this may often be the case) asylum seekers are supported with access to appropriate mental health support.

Participants also presented ordinary hopes and desires for the future, and one of these hopes was to be able to work. Given the extremely stringent rules which only allow asylum seekers to work in specific circumstances (Gower, 2011) and in practice prevent them from working, our participants were unable to gain employment. It is therefore recommended that all asylum seekers, regardless of the stage of their claims, are allowed to work. This would prevent them from being dependent on the state and would mean that they would be able to make a positive financial contribution, while giving positive benefits for their mental health and resulting in better social integration (see for example, Strijk et al., 2011). More integration would increase asylum seekers' wellbeing, and also reduce hostility towards them, as they would be able to contribute to society. The argument that allowing asylum seekers to work would act as a 'pull factor' to make them come to the UK (see Gower, 2011) seems out of step with the finding that asylum seekers tend not to actively choose the UK as a destination, and when they do it is because it is deemed to be safe, rather than economically easy.

\section{Limitations of the Research}

Although qualitative research concerns participants' in-depth accounts, it is acknowledged that a small sample size was used for the current study and therefore there are limitations regarding the information gained and its generalizability. The current research used a purposive sample and participants were selected according to the expertise they had based on their experiences of all being asylum seekers. Romney et al. (1986, p.326) argue that small samples can be sufficient in providing complete and accurate information within a cultural context as long as the participants possess a certain degree of expertise regarding the subject of inquiry. Indeed, they calculated that samples as small as four participants can render extremely accurate information with a high confidence level if they possess a high degree of competence for the subject of inquiry. 


\section{Conclusion}

The current study constitutes an important contribution to the literature on asylum seeking, as it fully engaged with asylum seekers about their own lived experiences. The findings demonstrate that asylum seekers are the UK for reasons of safety, rather than financial gain, which shows that asylum seekers are people who have fled from genuine persecution. Asylum seekers are a group who face hostility in the UK, and they have a lack of support and security in the UK which leads to isolation and mental health issues. This research highlights that asylum seekers want to make a contribution to the UK as well as live there for safety. It is recommended that greater emphasis be placed on providing safety and support for asylum seekers.

\section{References}

Benham, B. (2004), "Refugees' Convoy of Social Support", International Journal of Mental Health, Vol. 32 No 4, pp. 6-19.

Bernardes, D., Wright, J., Edwards, C., Tomkins, H., Dlfoz, D. and Livingstone, A. (2010), "Asylum seekers' Perspectives on their Mental Health and Views on Health and Social Services: Contributions for Service Provision Using Mixed-Methods Approach", International Journal of Migration, Health and Social Care, Vol. 6 No. 4, pp. 3-19.

Bloch, A. (2013) "Living in Fear: Rejected asylum seekers living as irregular migrants in England." Journal of Ethnic and Migration Studies doi:10.1080/1369183X.2013.859070

Bloch, A. and Schuster, L. (2002), "Asylum and welfare: Contemporary debates", Critical Social Policy, Vol. 22 No. 3, pp. 393-414.

Boyatzis, R. E. (1998). Transforming qualitative information: Thematic analysis and Code development. Thousand Oaks, CA: Sage. 
Braun, V. and Clarke, V. (2006), "Using Thematic Analysis in Psychology", Qualitative Research in Psychology, Vol. 3 pp. 77-101.

Capdevila, R. and Callaghan, J. (2008), “It's Not Racist, It's Common Sense'. A Critical Analysis of Political Discourse around Asylum and Immigration in the UK”, Journal of Community and Applied Social Psychology, Vol. 18 pp.1-16.

Darling, J. (2011), “Domopolitics, Governmentality and the Regulation of Asylum Accommodation", Political Geography, Vol. 30 No. 5, pp. 263-271.

Deuchar, R. (2011), "People look at us, the way we dress, and they think we're gangsters': Bonds, bridges, gangs and refugees: A qualitative study of intercultural social capital in Glasgow”, Journal of Refugee Studies, Vol. 24 No. 4, pp. 672-689.

Dorling, K. and Hurrell, A. (2012) Navigating the System: Advice Provision for Young Refugees and Migrants. Coram Children's Legal Centre.

Dorling, K., Girma, M. and Walter, N. (2012) Refused: The Experiences of Women Denied Asylum in the UK. Women for Refugee Women.

Fozdar, F. (2009), “The Golden Country’: Ex-Yugoslav and African Refugee Experiences of Settlement and 'Depression'", Journal of Ethnic and Migration Studies, Vol. 35 No. 8, pp. 1335-1352.

Gilbert, A. and Koser, K. (2004), "Coming to the UK: What do Asylum Seekers know before Arrival?" Journal of Ethnic and Migration Studies, Vol. 32 No. 7, pp. 1209-1225.

Gower, M. (2013) Asylum: Financial Support for Asylum Seekers. Home Affairs Section. House of Commons. www.parliament.uk/briefing-papers/SN01909.pdf 
Gower, M. (2011) Asylum Seekers and the Right to Work. Home Affairs Section. House of Commons. http://www.parliament.uk/briefing-papers/SN01908.pdf

Gower, M. and Hawkins, O. (2013) Immigration and Asylum Policy: Government Plans and Progress Made. Home Affairs Section: Social and General Statistics Section. House of Commons. http://www.parliament.uk/briefing-papers/SN05829.pdf

Hardy, C. (2003), "Refugee determination: Power and resistance in systems of Foucauldian power", Administration \& Society, Vol. 35 pp. 462-488.

Hynes, T. and Sales, R. (2009), "New communities: Asylum seekers and dispersal", A. Bloch. \& J. Solomos (Eds). In, Race and ethnicity in the 21st century, Aldershot: Palgrave Macmillan, pp.39-61.

Kirkwood, S. (2012), "Negotiating the Dilemmas of Claiming Asylum: A Discursive Analysis of Interviews with Refugees on Life in Scotland", esharp, pp. 87-112.

Lawrence, C. (2004), "Mental Illness in Detained Asylum Seekers", Lancet, Vol.364 pp. 1283-1284.

Leudar, I., Hayes, J., Nekvapil, J. and Turner Baker. J. (2008), "Hostility Themes in Media, Community and Refugee Narratives", Discourse and Society Vol. 19 pp. 187-221.

McKeary, M. and Newbold, B. (2010), "Barriers to Care: The Challenges for Canadian Refugees and their Health Care Providers", Journal of Refugee Studies, Vol 23 No 4, pp.523-545.

Mulvey, G. (2010), "When policy creates politics: The problematizing of immigration and the consequences for refugee integration in the UK".Journal of Refugee Studies, Vol. 23 pp. 437-462. 
Neumayer, E. (2005), “Bogus Refugees? The Determinants of Asylum Migration to Western Europe”, International Studies Quarterly, Vol. 49 pp. 389-409.

Refugee Council (2012), "The Facts about Asylum", available at: http://www.refugeecouncil.org.uk/practice/basics/facts (accessed 01 May 2012).

Romney, A., Batchelder, W. and Weller, S. (1986). Culture as consensus: A theory of culture and informant accuracy. American Anthropologist 88:pp. 313-38.

Rowthorne, R. (2008) The fiscal impact of immigration on the advanced economies. Oxford Review of Economic Policy, 24, 3, pp. 560-580

Sales, R. (2002), "The Deserving and the Undeserving? Refugees, Asylum Seekers and Welfare in Britain", Critical Social Policy, Vol. 22 No. 3, pp. 455-478.

Schuster, S., and Bloch, L. (2002), "Asylum and welfare: Contemporary debates", Critical Social Policy. Vol. 22 pp. 393-414.

Smyth, G. and Kum, H. (2010), "When they don't use it they will lose it': Professionals, deprofessionalization and reprofessionalization: The case of refugee teachers in Scotland", Journal of Refugee Studies, Vol 23 pp. 503-522.

Souter, J. (2011), "A culture of disbelief or denial? Critiquing refugee status determination in the United Kingdom", Oxford Monitor of Forced Migration, Vol. 1 pp. 48-59.

Spicer, N. (2008), "Places of Exclusion and Inclusion: Asylum Seeker and Refugee Experiences of Neighbourhoods in the UK", Journal of Ethnic and Migration Studies. Vol. 34 No. 3, pp. 491-510.

Strijk, P.M., van Meijel, B. and Gamel, C.J. (2011), "Health and Social Needs of Traumatized Refugees and Asylum Seekers: An Exploratory Study", Perspectives in Psychiatric Care, Vol. 47 No. 1, pp. 48-55. 
United Nations High Commissioner for Refugees (2011), "The UK and Asylum". available at

http://www.unhcr.org.uk/about-us/the-uk-and-asylum.html (accessed 03 May 2012). 
Tables to accompany the manuscript "Understanding the experiences of asylum seekers"

Table 1: Details about Participants

\begin{tabular}{|l|l|l|l|l|l|}
\hline Participant & $\begin{array}{l}\text { Country of } \\
\text { Origin }\end{array}$ & Gender & Age & Current asylum Status & $\begin{array}{l}\text { Length of } \\
\text { time in } \\
\text { UK }\end{array}$ \\
\hline One & Afghanistan & Male & 28 & Appealing rejection & 10 years \\
\hline Two & Angola & Female & 41 & Awaiting decision & 8 years \\
\hline Three & Ivory Coast & Male & 29 & Appealing rejected claim & 9 years \\
\hline Four & Mauritius & Female & 33 & Appealing rejected claim & 2 years \\
\hline Five & Mauritius & Male & N/A & Awaiting decision & 2 years \\
\hline Six & Mauritius & Male & 38 & Awaiting decision & 3 years \\
\hline Seven & Malawi & Female & 33 & Appealing rejection & 7 years \\
\hline Eight & Ethiopia & Female & N/A & Appealing rejection & 4 years \\
\hline Nine & Kenya & Female & N/A & Awaiting decision & 9 years \\
\hline
\end{tabular}

Table 2: Thematic analysis of interviews

\begin{tabular}{|l|l|l|}
\hline Theme & Subtheme & Illustrative extract \\
\hline $\begin{array}{l}\text { 1. The importance } \\
\text { of safety }\end{array}$ & $\begin{array}{l}\text { Home Country } \\
\text { dangerous }\end{array}$ & $\begin{array}{l}\text { I don't remember any good days... } \\
\text { [there] always was fighting }\end{array}$ \\
\hline & $\begin{array}{l}\text { Britain perceived as safe } \\
\text { haven }\end{array}$ & $\begin{array}{l}\text { I like, safe country you know I don't } \\
\text { see any problem }\end{array}$ \\
\hline $\begin{array}{l}\text { 2. Negative } \\
\text { experiences of the } \\
\text { Home Office } \\
\text { System }\end{array}$ & $\begin{array}{l}\text { Unable to return home } \\
\text { due to fear }\end{array}$ & $\begin{array}{l}\text { I cannot go back because I face } \\
\text { death how can I go? }\end{array}$ \\
\hline & $\begin{array}{l}\text { It's hard when you don't know } \\
\text { what's going to happen to you know } \\
\text { you think about it every day }\end{array}$ \\
\hline lives & $\begin{array}{l}\text { Participants confused } \\
\text { over system and the } \\
\text { status of their application }\end{array}$ & $\begin{array}{l}\text { When you going asylum you don't } \\
\text { know anything...you don't know } \\
\text { what's going on in the Home Office }\end{array}$ \\
\hline
\end{tabular}




\begin{tabular}{|l|l|l|}
\hline & Inhumane treatment & $\begin{array}{l}\text { Some people coming to my house to } \\
\text { send me back like animal }\end{array}$ \\
\hline 3. Support & $\begin{array}{l}\text { Constraints to refugee } \\
\text { centre's support }\end{array}$ & $\begin{array}{l}\text { These people trying hard as well } \\
\text { but the problem is Home Office } \\
\text { they don't care }\end{array}$ \\
\hline & Insecure accommodation & $\begin{array}{l}\text { I don't have somewhere to relax I } \\
\text { just walk and walk...during the day } \\
\text { I don't have anything to eat }\end{array}$ \\
\hline & Feeling unsafe & $\begin{array}{l}\text { White people just throw eggs } \\
\text { everywhere punch the door make } \\
\text { me scared. }\end{array}$ \\
\hline Positive experience of & $\begin{array}{l}\text { They supporting me a lot very } \\
\text { good...those people their work it's } \\
\text { not easy }\end{array}$ \\
\hline $\begin{array}{l}\text { 4. Emotional } \\
\text { Effects }\end{array}$ & Friendships & $\begin{array}{l}\text { They help because normally we } \\
\text { black people stick together...we } \\
\text { help each other }\end{array}$ \\
\hline & Suicidal tendencies & $\begin{array}{l}\text { I would really prefer to kill myself } \\
\text { because my life is bad }\end{array}$ \\
\hline $\begin{array}{l}\text { 7. Positive } \\
\text { experiences of } \\
\text { living in the UK }\end{array}$ & $\begin{array}{l}\text { Feeling isolated and } \\
\text { trapped }\end{array}$ & $\begin{array}{l}\text { I'm just staying indoors, not going } \\
\text { anywhere }\end{array}$ \\
\hline Future \\
Family
\end{tabular}

